\title{
Vertical vegetation design decisions and their impact on energy consumption in subtropical cities
}

\author{
Y. Stav \& G. Lawson \\ Queensland University of Technology, Australia
}

\begin{abstract}
Vertical vegetation is vegetation growing on, or adjacent to, the unused sunlit exterior surfaces of buildings in cities. Vertical vegetation can improve the energy efficiency of the building on which it is installed mainly by insulating, shading and transpiring moisture from foliage and substrate. Several design parameters may affect the extent of the vertical vegetation's improvement of energy performance. Examples are choice of vegetation, growing medium geometry, north/south aspect and others. The purpose of this study is to quantitatively map out the contribution of several parameters to energy savings in a subtropical setting. The method is thermal simulation based on EnergyPlus configured to reflect the special characteristics of vertical vegetation. Thermal simulation results show that yearly cooling energy savings can reach $25 \%$ with realistic design choices in subtropical environments. The most important parameter is the aspect of walls covered by vegetation. Vertical vegetation covering walls facing north (south for the northern hemisphere) will result in the highest energy savings. In making plant selections, the most significant parameter is Leaf Area Index (LAI). Plants with larger LAI, preferably LAI $>4$, contribute to greater savings whereas $\mathrm{LAI}<2$ can actually consume energy. Change of growing medium thickness from $6 \mathrm{~cm}$ to $8 \mathrm{~cm}$ causes a dramatic increase in energy savings from $2 \%$ to $18 \%$. It is best to use a growing material with high water retention, due to the importance of evapotranspiration for cooling. Similarly, for increased savings in cooling energy, sufficient irrigation is required. To conclude, the choice of design parameters for vertical vegetation is crucial in making sure that it contributes to energy savings rather than energy
\end{abstract}


consumption. Optimal design decisions can create a dramatic sustainability enhancement for the built environment in subtropical climates.

Keywords: vertical vegetation, living walls, thermal simulation, energy consumption, sustainable design.

\section{Introduction}

\subsection{Vertical vegetation for sustainable built environment}

In recent years it has been suggested that integration of vegetation within the building envelope is a sustainable design strategy for the built environment. One of the expected contributions of vegetation in terms of sustainability is the improved thermal behaviour of buildings when covered with vegetation layers. While green roof implementation is becoming more prevalent, and the research for green roofs' energy efficiency accumulates into a significant body of knowledge, the implementation and research of vertical vegetation technologies is still sparse. In addition, vertical vegetation systems are typically very expensive (e.g. living wall panel systems) or very slow to mature (e.g. climbing vines on trellises) or both. Therefore, when vertical vegetation project is considered, it is beneficial to be able to make informative design decisions at an early stage. Another incentive to focus on vertical vegetation is its potential to cover large surface areas of building walls that are otherwise not used. In the urban context most vertical surfaces are merely a maintenance challenge whereas if "greened" these surfaces can serve as cooling engines, air purifiers, carbon sinks and be pleasing to the eye at the same time.

\subsection{Vertical vegetation design parameters}

Vertical vegetation can be designed in various ways. The first design decision for a living wall project is choosing the vertical vegetation system. The primary classification of vertical vegetation, as suggested by other authors [1, 2], differentiates between green façades and living walls. Green façades refer to vines and climbers that grow from the ground or from large containers at various locations around the building. The climbers are supported either by the wall itself (the traditional green façade) or by a supporting trellis/mesh. Living walls, on the other hand, consist of plants that grow from a vertical layer of growing medium. Within the living wall category, some of the systems are based on plants growing hydroponically, typically planted in layers of synthetic felt, while others are based on panels or pockets filled with a more traditional growing medium (e.g. potting mix). These were categorised by Kontoleon and Eumorfopoulou [3] as vegetated mat and modular living wall respectively (see Fig. 1).

Other design decisions include choosing the walls to be covered with vegetation, and the extent to which they are covered. The vegetation may only cover the bottom floors, or only strips between windows. It may cover the entire wall or leave the windows clear for uninterrupted view and light. 


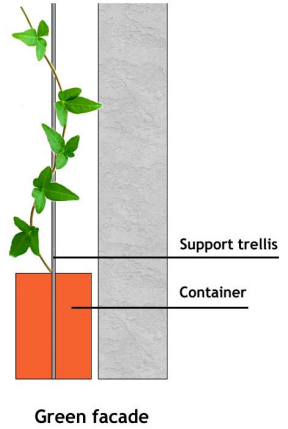

Figure 1: Schematic diagram of vertical vegetation types.

Decisions about plant selection have many impacts. It is important not only to make sure that the plants are suitable for the conditions, but also that they match their properties to the expectations of the people who use the building, maintenance plans, environmental considerations and the thermal behaviour required. Another important decision is the irrigation system: The living wall can survive with only local rainfall, but it is usually irrigated automatically (both in hydroponic systems and the modular systems) and it should be decided whether the water can be recycled, or whether grey water can be used. Energy modelling can assess how these design decisions influence energy consumption.

\section{Previous work}

Vertical vegetation, in addition to green roofs, can cool buildings in tropical and subtropical climates through their impact on shading the building, adding to exterior wall insulation, evaporating moisture from the growing substrate and transpiring moisture from leaf surfaces. The thermal impact of eight different vertical greenery systems in a Singapore study [4] found that vertical vegetation can reduce the surface temperature of building facades in a tropical climate by up to $11.58^{\circ} \mathrm{C}$. In subtropical Hong Kong [5], vegetated cladding was found to reduce interior temperatures by up to $14.5^{\circ} \mathrm{C}$ and delay the transfer of solar heat. A model for estimating heat flux transmission of vertical vegetation system was developed and tested in Hong Kong [6]. It showed that a south facing vertical vegetation wall absorbs large amounts of heat flux due to evapotranspiration. Green façades, on the other hand [7], were shown to create a micro climate between the wall and the vegetation slightly lower temperatures and higher relative humidity (up to $7 \%$ more) in Mediterranean climate. Probably the first simulation-based study for vertical vegetation was a model of double-skin façade with plants [8] using measurements of real plants in a test facility and incorporating these properties in the model. The results demonstrated up to $19 \%$ savings in cooling energy consumption due to the shading effect of the vegetation. 
Only a couple of studies have investigated specific parameters of vertical vegetation and their affect on the cooling impact: A simulation of energy transfer, as well as Urban Heat Island (UHI) reduction of vertical vegetation [9] in a tropical climate, showed that full coverage of a building with vertical vegetation can significantly reduce the thermal transfer value of the building envelope. The efficiency depends heavily on the Leaf Area Index (LAI) of the vegetation. Another study [3] investigated the influence of orientation and covering percentage of vertical vegetation coverage in a Mediterranean climate. The conclusions were that the adequate incorporation of a plant-covered wall in a building envelope improved the building's energy efficiency, with a more pronounced effect on the east and west facing walls.

Thus it is recognised that vertical vegetation has a significant impact on decreasing the energy consumption of buildings. However little is as yet known about how design characteristics of plants and the vertical vegetation system itself (variables of wall aspect, extent of wall coverage, plant species selection, growing medium material and geometry, water availability) can be modified to influence the degree of impact.

\section{Methodology}

\subsection{Set of energy simulations}

In order to address the knowledge gap described above, a set of energy simulations were created, using a parametric study of the various vertical vegetation parameters in subtropical Brisbane, Australia. The energy simulation tool used was EnergyPlus, developed by the US Department of Energy. EnergyPlus is a whole building energy simulation program with a built-in module for green roofs [10] that was developed as a tool to inform green roof design decisions. The green roof module took into account the growing media characteristics, irrigation and vegetation characteristics, and accounts for shading and insulation effects as well as evapotranspiration from the substrate and plants. This module was validated with real experiments of green roofs including live vegetation. In this study, the simulations included "green roof" surfaces that were both horizontal and vertical in order to simulate green roof as well as green walls, i.e. vertical vegetation.

For this study, a simple building model was created, consisting of a single story rectangular area with two double pane windows, light walls and roofs typical to the subtropical buildings commonly used in Brisbane (wood, fibreglass and plasterboard). The air system assumed infinite cooling/heating regimes. The vertical vegetation model was schematic and consisted of a layer of growing medium, and a layer of vegetation. The vegetation covered the entire roof and walls, excluding the windows (see fig. 2). The weather file used was yearly Brisbane weather data created in 2006 based on data from 1967-2004. 

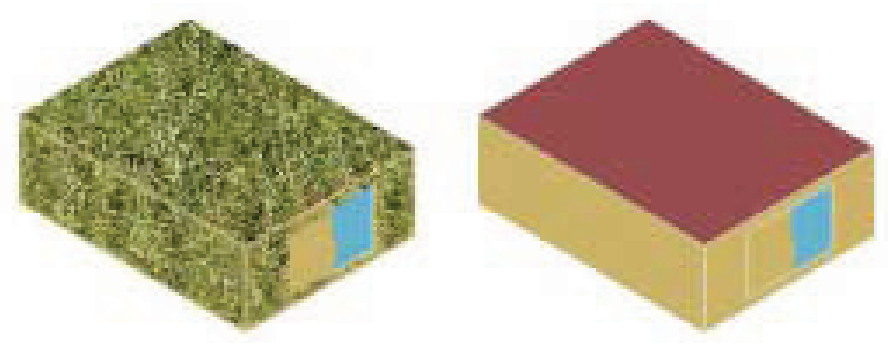

Figure 2: $\quad$ Schematic building with and without vegetation coverage.

Each simulation measured the amount of energy required for heating and cooling during an entire year, with a different set of parameter values. Yearly energy consumption for each simulation was then compared to the scenario with a bare building (without vegetation cover) (see fig. 2) in order to estimate the energy impact of the vegetation.

\subsection{Parametric study}

A baseline scenario was defined for comparison when studying the various parameters. The values of the baseline scenario parameters were picked so that this scenario was reasonable. The list of parameters and their values appears in Table 1. The table shows for each parameter the baseline value, as well as the minimum and maximum values used during the simulations. Some of the parameters are discussed below:

1. Height of Plants. The baseline value used was 0.3 metre since the estimated height for living walls was $0.1-0.5$ metre.

2. Leaf Area Index. In various green roof studies, the LAI was assumed to be around 3 - typical for green roofs with grass [11] and for ivy cover [12]. This was chosen as the baseline value for the LAI of plants in this study.

3. Thickness of Growing Medium. Green roofs have thicker growing media such as $15 \mathrm{~cm}$ or even $30 \mathrm{~cm}$ for intensive green roofs. However vertical vegetation can have no growing media at all (in the case of green façades) and typically has a slim growing medium of $5-10 \mathrm{~cm}$. The baseline value was therefore chosen as $8 \mathrm{~cm}$.

4. Irrigation was set for two hours each morning, and the irrigation rate used two different values, one for summer and the other for winter.

\section{Analysis}

\subsection{Heating energy vs. cooling energy}

When using the baseline parameter values with the Brisbane weather file, the results showed that most of the energy required for maintaining thermal comfort during the daytime (8:00-18:00) was cooling energy. In this scenario the 
Table 1: $\quad$ List of vertical vegetation parameters studied.

\begin{tabular}{|c|c|c|c|c|c|}
\hline & $\begin{array}{l}\text { Parameter Name } \\
\text { (in EnergyPlus) }\end{array}$ & $\begin{array}{l}\text { Baseline } \\
\text { value }\end{array}$ & Min & Max & Comments \\
\hline \multirow[t]{5}{*}{ Vegetation } & Height of Plants $\{\mathrm{m}\}$ & 0.3 & 0.01 & 1 & $\begin{array}{l}0.1-0.5 \text { are } \\
\text { reasonable for } \\
\text { living walls }\end{array}$ \\
\hline & $\begin{array}{l}\text { Leaf Area Index } \\
\{\text { dimensionless }\}\end{array}$ & 3.0 & 0.001 & 5 & \\
\hline & $\begin{array}{l}\text { Leaf Reflectivity } \\
\{\text { dimensionless }\}\end{array}$ & 0.22 & 0.1 & 0.4 & $\begin{array}{c}\text { Typically } 0.18- \\
0.25\end{array}$ \\
\hline & Leaf Emissivity & 0.95 & 0.8 & 1 & Default $=0.95$ \\
\hline & $\begin{array}{l}\text { Minimum Stomatal } \\
\text { Resistance }\{\mathrm{s} / \mathrm{m}\}\end{array}$ & 180 & 50 & 300 & \\
\hline \multirow[t]{8}{*}{$\begin{array}{l}\text { Growing } \\
\text { Medium }\end{array}$} & Roughness & $\begin{array}{l}\text { Medium } \\
\text { Smooth }\end{array}$ & & & $\begin{array}{l}6 \text { values from } \\
\text { VerySmooth to } \\
\text { VeryRough }\end{array}$ \\
\hline & Thickness $\{\mathrm{m}\}$ & 0.08 & 0.05 & 0.5 & $\begin{array}{l}0.15 \text { and } 0.30 \text { are } \\
\text { common for green } \\
\text { roofs. Living walls } \\
\text { are slimmer }\end{array}$ \\
\hline & $\begin{array}{l}\text { Conductivity of Dry Soil } \\
\qquad\{\mathrm{W} / \mathrm{m}-\mathrm{K}\}\end{array}$ & 0.4 & 0.2 & 1 & $\begin{array}{l}\text { Typically } 0.3-0.5 \\
\text { for green roof } \\
\text { substrate }\end{array}$ \\
\hline & $\begin{array}{c}\text { Density of Dry Soil } \\
\{\mathrm{kg} / \mathrm{m} 3\}\end{array}$ & 641 & 300 & 2000 & $\begin{array}{l}\text { Typically } 400- \\
1000\end{array}$ \\
\hline & $\begin{array}{l}\text { Specific Heat of Dry } \\
\text { Soil }\{\mathrm{J} / \mathrm{kg}-\mathrm{K}\}\end{array}$ & 1100 & 501 & 2000 & Default $=1000$ \\
\hline & Thermal Absorptance & 0.95 & 0.81 & 1 & $\begin{array}{c}\text { Typically } 0.90- \\
0.98\end{array}$ \\
\hline & Solar Absorptance & 0.8 & 0.4 & 0.9 & Typically 0.6-0.85 \\
\hline & Visible Absorptance & 0.7 & 0.51 & 1 & \\
\hline \multirow[t]{4}{*}{$\begin{array}{l}\text { Moisture in } \\
\text { Growing } \\
\text { Media }\end{array}$} & $\begin{array}{c}\text { Saturation Volumetric } \\
\text { Moisture Content of Soil } \\
\text { Layer }\end{array}$ & 0.4 & 0.11 & 1 & $\begin{array}{c}\text { Typically less than } \\
0.5\end{array}$ \\
\hline & $\begin{array}{c}\text { Residual Volumetric } \\
\text { Moisture Content of Soil } \\
\text { Layer }\end{array}$ & 0.01 & 0.01 & 0.1 & \\
\hline & $\begin{array}{c}\text { Initial Volumetric } \\
\text { Moisture Content of Soil } \\
\text { Layer }\end{array}$ & 0.2 & 0.11 & 1 & \\
\hline & $\begin{array}{l}\text { Irrigation Daily Rate } \\
\qquad\{\mathrm{cm} / \mathrm{hr}\}\end{array}$ & $0.2,0.1$ & 0 & 0.3 & $\begin{array}{c}\text { The values } \\
\text { represent rates for } \\
\text { summer and } \\
\text { winter, set for } 2 \\
\text { hours every } \\
\text { morning }\end{array}$ \\
\hline \multirow[t]{3}{*}{$\begin{array}{c}\text { HVAC } \\
\text { Thermostat }\end{array}$} & $\begin{array}{l}\text { Thermostat Set-Points } \\
\qquad\left\{{ }^{\circ} \mathrm{C}\right\}\end{array}$ & $20-24$ & & & $\begin{array}{c}\text { Tested with } 19- \\
25^{\circ} \mathrm{C} \text { and } 21-23^{\circ} \mathrm{C} \\
\end{array}$ \\
\hline & Thermostat Schedule & Always & & & $\begin{array}{l}\text { Tested with daily } \\
\text { schedule 8:00- } \\
18: 00\end{array}$ \\
\hline & Living Wall Aspects & $\begin{array}{c}\text { All } \\
\text { aspects }\end{array}$ & & & $\begin{array}{c}\text { North, South, East, } \\
\text { West and } \\
\text { combinations }\end{array}$ \\
\hline
\end{tabular}


vegetation saved $690,530 \mathrm{~kJ}$ per year for cooling and only $4,417 \mathrm{~kJ}$ per year for heating (See Table 2).

The results showed that for the subtropical Brisbane, heating energy savings were negligible and therefore in the rest of the work only cooling energy was considered in further scenarios.

Table 2: $\quad$ Yearly heating and cooling energy savings.

\begin{tabular}{|c|c|c|c|c|}
\hline & \multicolumn{2}{|c|}{ Cooling } & \multicolumn{2}{c|}{ Heating } \\
\cline { 2 - 5 } & Total $[\mathrm{kJ}]$ & $\begin{array}{c}\text { Energy } \\
\text { Savings }\end{array}$ & Total [kJ] & $\begin{array}{c}\text { Energy } \\
\text { Savings }\end{array}$ \\
\hline Bare Building & $3,895,287$ & -- & 9,506 & -- \\
\hline $\begin{array}{c}\text { Building w Green Roof \& } \\
\text { Vertical Vegetation }\end{array}$ & $3,204,757$ & 690530 & 5,089 & 4417 \\
\hline
\end{tabular}

\subsection{Layout selection}

A set of simulations examined the impact of the direction of the vertical vegetation. Different simulations of the building were used with only one or two of the walls covered with vegetation. The results can be seen in table 3 .

Table 3: Cooling energy savings of wall-facing aspects.

\begin{tabular}{|c|c|c|c|}
\hline \multirow{2}{*}{} & & \multicolumn{2}{|c|}{} \\
\cline { 2 - 4 } & Living wall cover & Total $[\mathrm{kJ}]$ & Energy Savings \\
\hline Bare Building & NA & $3,895,287$ & \\
\hline Building with green roof only & NA & $3,299,674$ & $15 \%$ \\
\hline \multirow{3}{*}{$\begin{array}{c}\text { Building with green roof } \\
\text { and living wall/s }\end{array}$} & all aspects & $3,204,757$ & $18 \%$ \\
\cline { 2 - 4 } & north & $2,973,047$ & $24 \%$ \\
\cline { 2 - 4 } & east & $3,230,621$ & $17 \%$ \\
\cline { 2 - 4 } & south & $3,467,318$ & $11 \%$ \\
\cline { 2 - 4 } & west & $3,154,473$ & $19 \%$ \\
\cline { 2 - 4 } & north west & $2,918,924$ & $25 \%$ \\
\cline { 2 - 4 } & north east & $24 \%$ \\
\hline
\end{tabular}

Although covering the entire wall envelope of the building with vegetation improved energy savings by only $3 \%$ over the $15 \%$ improvement achieved by green roof alone, covering only the north facing wall with vegetation supplied an additional $9 \%$ in energy savings adding to the $24 \%$ total savings. On the other hand, covering only the south facing wall brought the total savings down to only $11 \%$, making it an energy burden. The best configuration was having a green roof and living walls facing the north and west aspects of the building, reaching $25 \%$ total energy savings. 


\subsection{Plant selection}

Some parameters of the vegetation itself were found to be significant for energy consumption. The most important parameter was LAI (Leaf Area Index). LAI dramatically changed savings on cooling energy since it indirectly measured both the size of the plant as well as the relative size of its leaves. Using small values for LAI, it was shown that vertical vegetation with tiny leafed plants or no plants at all caused warming and therefore required even more cooling energy than the bare building scenario. Mycrophyll plant species have a lower ability to shed heat. This stressed the importance of vertical vegetation not just as an additional layer of matter, but also as an active vegetation layer that allowed evapotranspiration processes to occur. The optimal LAI values that were tested were 4 or 5 , but even $\mathrm{LAI}=3$ created a significant energy savings impact.

Other vegetation parameters also influenced the effectiveness of cooling by the vertical vegetation. This included the following:

1. Minimum stomatal resistance (MSR) indicated the leaves' stomatal behaviour with regards to evaporating water. Minimal and maximal values of MSR from 50 to 300 resulted in energy savings range of 15$22 \%$.

2. Vegetation Height increases resulted in small linear increases in energy savings (see fig. 3).

3. Leaf Reflectivity increases resulted in increases in cooling savings ranging from $11 \%$ to $22 \%$.

4. Leaf Emissivity increases resulted in some increases in cooling savings ranging from $15 \%$ to $19 \%$.

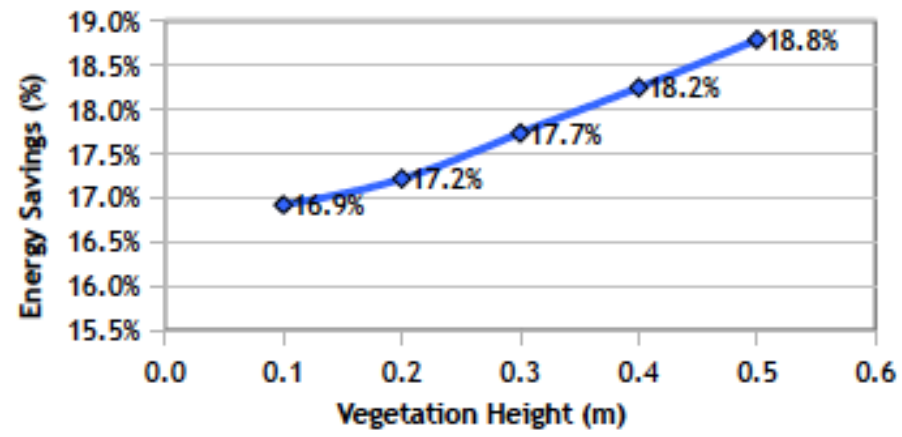

Figure 3: Cooling energy savings vs. vegetation height.

\subsection{Growing medium selection}

Changing of the parameters that characterise the growing medium (called here substrate for short) influences energy consumption for both heating and cooling. The important parameters are substrate thickness and substrate conductivity.

Thickness of the growing medium is a significant parameter for both heating and cooling, indicating that this layer serves as an insulation layer. Change of a 
couple of centimetres in substrate thickness from $6 \mathrm{~cm}$ to $8 \mathrm{~cm}$ causes dramatic energy consumption changes from $2 \%$ to $18 \%$.

\subsection{Irrigation}

Most parameters related to irrigation and moisture significantly change the capacity of the vertical vegetation to cool the building: Higher water retention by the growing medium improves cooling - indicating the importance of evaporation from the growing medium to the cooling effect of the substrate (for example, see fig. 4).

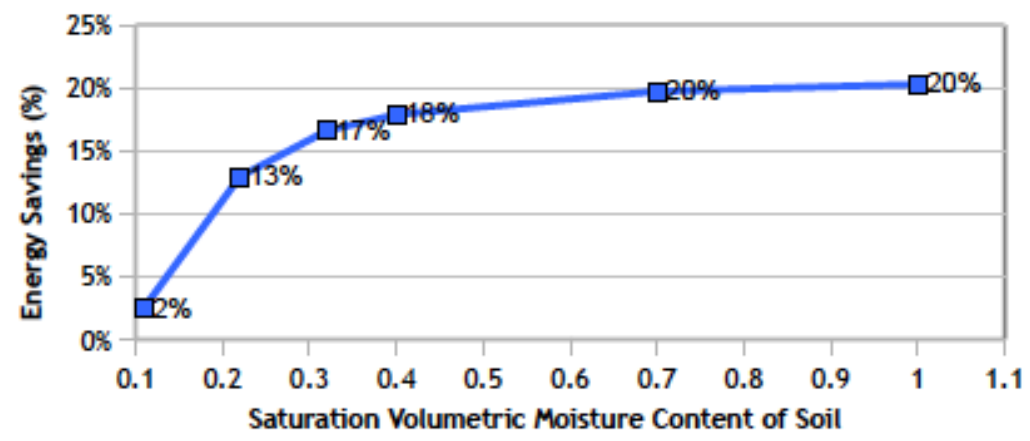

Figure 4: Cooling energy vs. saturation moisture content of substrate.

Sufficient irrigation is also important for cooling of the vertical vegetation. If the irrigation is missing then vertical vegetation will increase the energy required to cool the building. If irrigation is sufficient (around $1 \mathrm{~mm} / \mathrm{hr}$ for 2 hours a day in the case of this simulation) then the vertical vegetation will reduce energy consumption, whereas if the amount is higher than $2 \mathrm{~mm} / \mathrm{hr}$, and keeps the growing medium and vegetation moist, then cooling energy reduction can go up to $20 \%$ (see fig. 5 ).

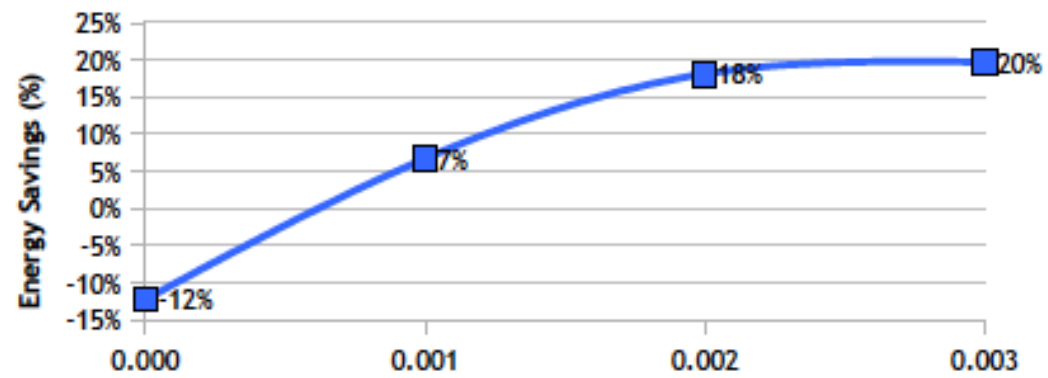

Amount of Irrigation 7:00-9:00 AM (m/hr)

Figure 5: Cooling energy vs. irrigation amounts. 
Thus it is shown that irrigation and moisture behaviour in the vertical vegetation system are very important to cooling due to evapotranspiration.

\section{Discussion and conclusions}

It was shown by earlier studies that vertical vegetation can save cooling/heating energy of buildings [13-15]. Since there is a wide selection of vertical vegetation systems and various ways to implement them and plant them, it is important to use informed design decisions for designers/architects to establish vertical vegetation projects that contribute to energy efficiency of buildings.

This research was focused on green roofs and vertical vegetation in subtropical Brisbane and used energy simulation software that took into account various thermal processes related to vertical vegetation including evaporative cooling by leaves and substrate, shading, insulation and wind. The simulation method, via parameter study, allowed testing of a range of values for various parameters of vertical vegetation, resulting in data that was equivalent to testing dozens of different vertical vegetation projects.

As described earlier, a study of the various wall directions and coverage was performed for a Mediterranean climate context and showed that west and east facing walls were most important [3]. In our Brisbane study, the impact of the direction of the vertical vegetation showed that significant reductions in energy consumption were possible with only the north facing wall covered with vegetation. This study also showed that it was best to use growing substrate that was thicker than $8 \mathrm{~cm}$, with dense vegetation (LAI $>2$ ) and adequate irrigation.

Thus vertical vegetation systems that have not used well-considered design parameters are unlikely to result in expected energy saving outcomes. Vertical vegetation may actually increase the amount of energy required to cool a building. The results yielded a set of design characteristics that can be useful for vertical vegetation designers in order to create a more sustainable city.

\section{Future work}

These simulation parameters remain theoretical and were based on a simple building representation. This simulation model was not sophisticated enough to simulate various family houses or commercial buildings in Brisbane. Running this simulation with a larger building type of greater thermal mass would be expected to decrease the influence of the vegetation and substrate as simply an insulation layer. In addition, the simulation does not take into account internal gains (people and equipment inside the building). Similar simulations should be conducted with larger, more complex buildings, preferably those appropriate to the Brisbane Central Business District where the greatest heat island effect is experienced. The simulated building should include other parameters such as thermal zones, shading devices and internal gains (heating generated by people and equipment).

The simulation model itself has a few technical drawbacks. It was based on a green roof module and was not planned as a vertical surface. One of the 
challenges here was that the vertical vegetation use approximate wind and moisture calculations. A few improvements to the simulation code should be performed in order to increase accuracy.

Being theoretical, this study ignored the botanical/horticultural aspect, as it was assumed that there would be plants found with specified characteristics to suit the use on vertical surfaces. It was assumed that they would thrive within the given conditions of light, wind and irrigation. It would also be preferable to use real plant species or combination of species, with their corresponding parameters (mainly LAI), to allow simulation of realistic choices of vegetation. Soil materials should also be modelled using real materials suitable as living wall substrates (i.e. rockwool, synthetic felt, hydrocell etc). The real physical properties of these materials, such as their thermal conductivity and water retention, should be used within the simulation. Much work has yet to be done in refining this simulation approach.

\section{References}

[1] Dunnett, N. \& Kingsbury, N., Planting green roofs and living walls, Timber Press: Portland, Or. and Cambridge, U.K., pp. 254, 2004.

[2] Kohler, D.M., Living Wall Systems - A View Back and Some Visions. Fourth Annual Greening Rooftops for Sustainable Communities. Boston, 2006.

[3] Kontoleon, K.J. \& Eumorfopoulou, E.A., The effect of the orientation and proportion of a plant-covered wall layer on the thermal performance of a building zone. Building and Environment, 45(5), pp. 1287-1303, 2010.

[4] Wong, N.H., Tan, A.Y.K., Chen, Y., Sekar, K., Tan, P.Y., Chan, D., Chiang, K. \& Wong, N.C., Thermal evaluation of vertical greenery systems for building walls. Building and Environment, 45(3), pp. 663-672, 2010.

[5] Cheng, C.Y., Cheung, K.K.S. \& Chu, L.M., Thermal performance of a vegetated cladding system on facade walls. Building and Environment, 45(8), pp. 1779-1787, 2010.

[6] Jim, C.Y. \& He, H., Estimating heat flux transmission of vertical greenery ecosystem. Ecological Engineering, 37(8), pp. 1112-1122, 2011.

[7] Perez, G., Rincon, L., Vila, A., Gonzalez, J.M. \& Cabeza, L.F., Green vertical systems for buildings as passive systems for energy savings. Applied Energy, 88(12), pp. 4854-4859, 2011.

[8] Stec, W.J., van Paassen, A.H.C., \& Maziarz, A., Modelling the double skin façade with plants. Energy and Buildings, 37(5), pp. 419-427, 2005.

[9] Wong, N.H., Tan, A.Y.K., Tan, P.Y. \& Wong, N.C., Energy simulation of vertical greenery systems. Energy and Buildings, 41(12), pp. 1401-1408, 2009.

[10] Sailor, D.J., A green roof model for building energy simulation programs. Energy and Buildings, 40(8), pp. 1466-1478, 2008.

[11] Currie, B.A \& Bass, B., Estimates of air pollution mitigation with green plants and green roofs using the UFORE model. Urban Ecosystems, 11(4), pp. 409-422, 2008. 
[12] Takakura, T., Kitade, S. \& Goto, E., Cooling effect of greenery cover over a building. Energy and Buildings, 31(1), pp. 1-6, 2000.

[13] Eumorfopoulou, E.A. \& Kontoleon, K.J., Experimental approach to the contribution of plant-covered walls to the thermal behaviour of building envelopes. Building and Environment, 44(5), pp. 1024-1038, 2009.

[14] Kohler, M., Green facades, A view back and some visions. Urban Ecosystems, 11(4), pp. 423-436, 2008.

[15] Perini, K., Ottele, M., Fraaij, A.L.A, Haas, E.M. \& Raiteri, R., Vertical greening systems and the effect on air flow and temperature on the building envelope. Building and Environment, 46(11), pp. 2287-2294, 2011. 